Case Report

\title{
Warfarin Induced Spontaneous Posterior Fossa Extradural Hematoma
}

Peer Asad Aziz, Riaz.A.Raja, Sanaullah Pathan, Ali Abbas, Rabail Abro \& Almas Abro

Liaquat University of Medical \& Health Sciences (LUMHS)

Corresponding Author: asad@aeirc-edu.com

\section{Background}

Posterior fossa EDH (PFEDH) is one entity which is quite uncommon and spontaneous /Drug induced PFEDH is one of most rare radiological finding.

\section{Material and Method}

This case study was reported from department of neurosurgery Liaquat University of Medical Health Sciences Jamshoro. A 28yrs old male patient, known case of DVT, presented to emergency department with severe head ache since last 12 hrs. Head ache initially started 3 days before it became severe and gradual, constant localized to occipital region with no aggravating and relieving factors. It was associated with vomiting 5-6 episodes; patient had also previous history of hospitalization for DVT and history of appendectomy 6 years back. He had no history of trauma or blow to head and had no history of D.M II or HTN like other familial diseases.

Patient was taking anticoagulants for last $12 \mathrm{yrs}$ and from last 5 months he started taking warfarin $5 \mathrm{mg}$ tablet twice a day as he was advised by some General practioner. He had no history of addiction to anything. On examination, he was well oriented, communicative non-canalized, noncatharized with normal blood pressure and pulse. He had bluish spots over skin his GCS at time of presentation was 14/15and rest of neurological examination was normal after history and examination. Brain CT was done, that showed posterior fossa EDH (PFEDH), which is very unusual and rare finding on imaging to occur spontaneously without any history of trauma. According to our best of knowledge previously only 18 cases of spontaneous PFEDH were reported till date since $1951^{1}$. In past, such case has been reported after cardiac surgery for tricuspid area in 4 years male child ${ }^{2}$.

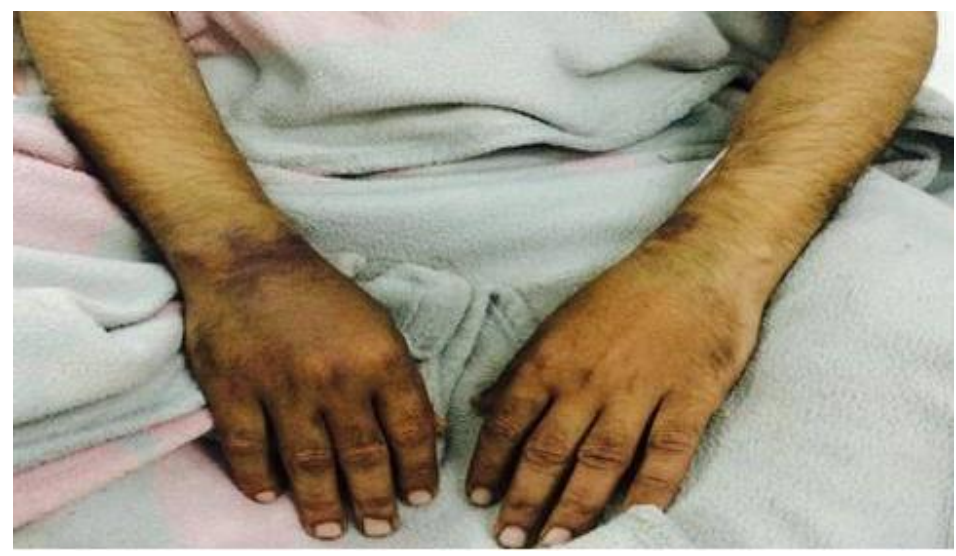




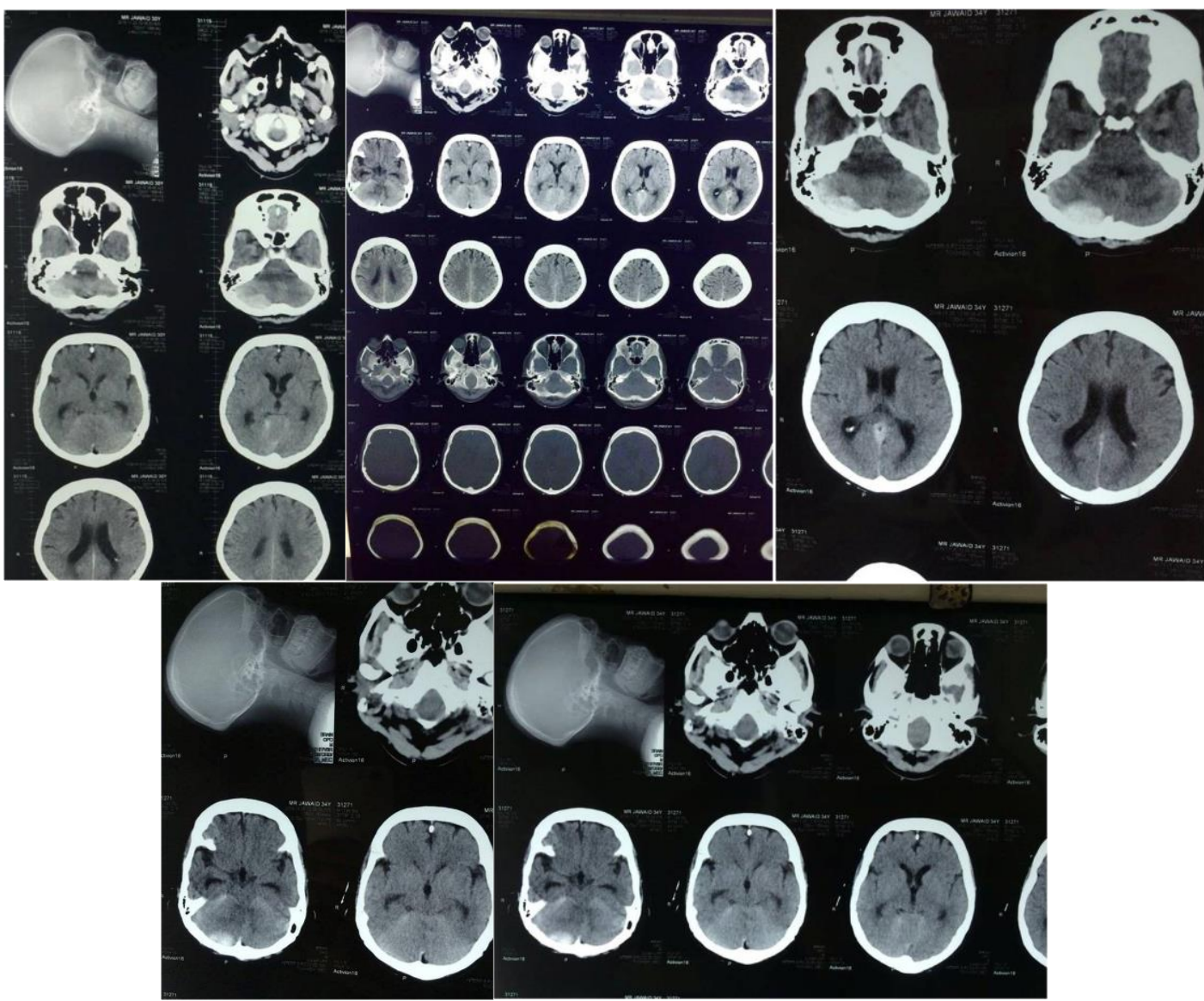

\section{Conclusion}

Anticoagulants like warfarin are beneficial drugs and have potential to cause havoc for patients if taken in appropriately so strict monitoring should be done prior and after administration by making it a routine. This case refreshes and adds on the knowledge about PFEDH to occur spontaneously after high dose of warfarin therapy3. According to our knowledge this is only 2 nd case to be reported as PFEDH after anticoagulant therapy.

\section{References}

1. Ahmad FU, Pandey P, Mahapatra AK. Spontaneous Posterior Fossa Extradural Hematoma-A Rare Complication following Cardiac Surgery. Pediatric neurosurgery. 2005 May 2; 41(1):49-51. 2. Kumar, B., Bhagat, H., Raj, R., \& Jayant,
A. (2013). Extradural hematoma following double valve replacement under cardiopulmonary bypass: A rare complication. Annals of cardiac anesthesia, 16(1), 58 .

3. Zheng FX, Chao Y. Spontaneous intracranial extradural hematoma: case report and literature review. Neurology India. 2009 May 1; 57(3):324. 